Research Journal of Applied Sciences, Engineering and Technology 16(4): 135-139, 2019

DOI: $10.19026 /$ rjaset.16.6017

ISSN: 2040-7459; e-ISSN: 2040-7467

(C) 2019 Maxwell Scientific Publication Corp.

Submitted: November 14, 2018

Accepted: December 27, 2018

Published: September 15, 2019

\title{
Research Article Improvement of an Alluvial Gravel Geotechnical Properties with a Clayey Soil for the Road Construction
}

\author{
${ }^{1}$ Raymond G. Elenga, ${ }^{1,2}$ Louis Ahouet, ${ }^{1}$ Mondésir Ngoulou, ${ }^{1}$ Stévina Bouyila, \\ ${ }^{3}$ Guy F. Dirras and ${ }^{2}$ Eric Kengué \\ ${ }^{1}$ Laboratoire des Matériaux et Énergies, FST, Marien Ngouabi University, B.P. 69, Brazzaville, Congo \\ ${ }^{2}$ Bureau de Con trôle du Bâtiment et Travaux Publics, B.P. 72, Brazzaville, Congo \\ ${ }^{3}$ Laboratoire des Sciences des Procédés et Matériaux, CNRS, Université Paris 13, Sorbonne Paris \\ Cité, 99 av. Jean-Baptiste Clement, 93430 Villetaneuse, France
}

\begin{abstract}
The aim of this study is to characterize the alluvial gravel of the Niari river in Congo, to improve its geotechnical properties by stabilizing it with a clayey soil and to find out its utilization in the road construction according to the approved standards in most African countries. The results show that the grain size distribution of the alluvial gravel fits in the standard envelope of the base layer and its resistance to friction of $23 \%$ is within the allowed limits. However, its fines content and plasticity index are respectively 4 and $0 \%$, out of the allowed range. Adding the clayey soil increases the CBR index from 0 for the alluvial gravel to $142 \%$ for a mixture of $15 \%$ of the clayey soil, while the sand equivalent decreases from 80 to $42 \%$. The mixtures of 5, 10 and $30 \%$, respectively of the clayey soil content could be used as the subbase layer in the road construction; that of $15 \%$ as the base layer for T3 and T4 traffics and those of 20 and $25 \%$ as the base layer for T1 and T2 traffics. Besides, it is found that the CBR index of the mixture of the CBR index is strongly correlated to its density and the relationship between them is parabolic.
\end{abstract}

Keywords: Alluvial gravel, clayey soil, geotechnical properties, litho-stabilization, road

\section{INTRODUCTION}

In the developing countries, the road network is usually characterized by a low traffic density and a poor condition. Construction and maintenance costs remain high in relation to their incomes and roads often deteriorate prematurely (Sangaré and Atiase, 1991; Economic Commission for Africa, 2007; Kana, 2016). Nowadays, for a sustainable development, it is necessary to consider not only the technical specifications and the direct costs of the structures, but also the environmental impacts (the depletion of the non-renewable resources, the consequences on the flora and the fauna, the gas emissions, the noise, the degradation of the existing roads due to the transport of materials, ...) and social impacts (employment, land occupation, population migrations, etc.) (Sinha et al., 1990; Correia et al., 2016.) Therefore, the use of local unconventional materials (natural or recycled) can be a good alternative in some cases (Weinert, 1980; Sinha et al., 1990; Molenaar, 2013; Correia et al., 2016). For this purpose, it is important to have reliable data on the geotechnical characteristics of these materials and to adopt local standards based on these materials and their interactions with the local environment that is to say, their in-situ behavior. Indeed, in one hand, several studies report that although some local materials, as lateritic soils for instance, do not fulfill the European or American standards but have proven to be good in use. On the other hand, some roads constructed in accordance with these same standards have prematurely deteriorated (Toll, 1991; Cocks et al., 2015; PaigeGreen et al., 2015; Camapum de Carvalho et al., 2015; Kana, 2016).

However, studies on unconventional materials for the roads' construction in Africa are scarce. The existing studies deal mainly with lateritic soils due to their abundance (Bohi, 2008; Quadri et al., 2012; Ndiaye, 2013; Issiakou, 2016; Onana et al., 2017). It has been shown that the bearing capacity of the lateritic soils is improved by reducing their clay content by adding incoherent materials (sand, palm kernels, crushed stones, etc.). However, in the rainy areas, the paved roads with lateritic soils are degraded within two years at most. In the dry season, they release a lot of dust that pollutes everything around and usually cause accidents as the visibility is reduced. In Congo, for example, before the asphalting of the National road $n^{\circ} \mathrm{I}$, the users and the transported goods by this road were easily recognized by their ocher color, the laterite color

Corresponding Author: Raymond G. Elenga, Laboratoire des Matériaux et Énergies, FST, Marien Ngouabi University, B.P. 69, Brazzaville, Congo

This work is licensed under a Creative Commons Attribution 4.0 International License (URL: http://creativecommons.org/licenses/by/4.0/). 
of this region. In the rainy season on the contrary, these roads become sticky and slippery due to their high clay content. Thus, these roads require a permanent maintenance (leveling and new soil supply) and the use of this non-renewable resource in this application appears to be questionable.

Fortunately, other solutions exist. For instance, beds of some rivers are rich in the alluvial gravel with a good skeleton. But, unlike lateritic soils, the alluvial gravels have the drawback of being incoherent. Thus, the incorporation of a binding product could improve their geotechnical properties and make them suitable for roads' construction.

The aim of this study is to characterize, at the first time, the crushed alluvial gravel $0 / 31.5$ of the Niari River in south Congo and to improve its cohesion by adding a clayey soil for its use in the body of the roadway, in accordance with specifications of roads for the Centre Expérimental de recherches et d'études du Bâtiment et Travaux Publics (CEBTP) (1980), usually used in most sub-Saharan African countries.

\section{MATERIALS AND METHODS}

This alluvial gravel used was collected in the bed of the Niari river in the south area of Congo and the clayey soil used was collected about $1000 \mathrm{~m}$ from the gravel site.

The grain size distributions of these two soils and their mixtures were determined by sieving and sedimentation in accordance with the standards NF EN 13285 (2006), NF P94-056 (1996) and NF P94-057 (1992).

The maximum dry density was measured through the modified Proctor test according to the standard NF P94-093 (1999). To determine the plasticity of the soils, Atterberg limits were measured according to the standard NF P94-051 (1993).

The bearing capacity of the soils was valued through the Californian Bearing Ratio (CBR) test and the compressive strength measurement. The CBR test was performed in accordance with the standard NF P94-078 (1997). Measurements of the compressive strength were made on samples of $10 \mathrm{~cm}$ in diameter and $20 \mathrm{~cm}$ in height according to the standard NF EN 13286-41 (2007).

The sand equivalent and the Los Angeles tests of the alluvial gravel were respectively carried out following standards NF P18-597 (1990) and NF P18573 (1990).

The formulation of the different road layers based on the mixtures of the two soils was carried out according to the following protocol: after mixing the two soils with the selected proportions until homogenization, the grain size curve of the mixture was determined to ensure that it remains within the standard envelope. Then, the CBR index, the optimum Proctor and the compressive strength of the mixture were measured to determine its use.

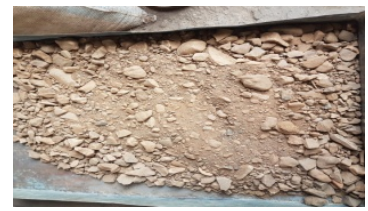

(a)

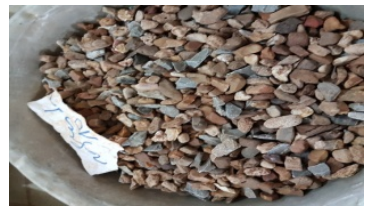

(b)
Fig. 1: Photos of the alluvional gravel 0/31.5 (a) before and (b) after washing

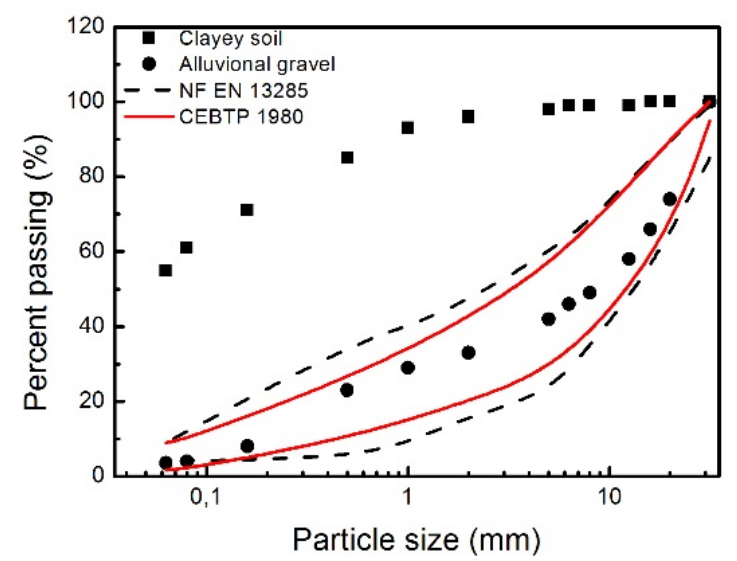

Fig. 2: Grading grain size curves of the alluvional gravel and the clayey soil compared respectively with the standard envelopes of European standard (NF EN 13285, black dashed line) and the Centre Expémitental du Bâtiment et Travaux Publics standard (CEBTP 1980, red solid line)

\section{RESULTS AND DISCUSSION}

Geotechnical characteristics of the alluvial gravel: Figure 1 shows the alluvial gravel $0 / 31.5$ before (a) and after the washing (b). The grain's shape is variable. The grading grain size curve of the washed alluvial gravel is reported in Fig. 2 with that of the clay soil as well as the grading envelopes for the base layers defined by the standards NF EN 13285 and the CEBTP 1980.

As it can be seen, the grading curve of the washed alluvial gravel fits well into the recommended envelopes. But its content of grains smaller than $0.15 \mathrm{~mm}$ is at the minimum allowed. This explains its lack of cohesion and the impossibility of measuring its CBR index. However, the percentage of grains smaller than $0.5 \mathrm{~mm}$ is close to the upper limit of the particle size distribution recommended by the CEBTP (1980). Consequently, the percentage of fines to be added must remain limited to avoid the fact of getting out of the envelope. Moreover, it has good friction resistance since its Los Angeles coefficient is of $23 \%$ (Table 1 ), less than the maximum of $35 \%$ required by the CEBTP 1980. However, the sand equivalent of the alluvial gravel is $80 \%$ (Table 1). Thus, this alluvial gravel is suitable for the manufacture of the mortar and 
Table 1: Geotechnical characteristics of the alluvional gravel and the

\begin{tabular}{|c|c|c|c|}
\hline \multicolumn{2}{|l|}{ Characteristics } & \multirow{2}{*}{$\begin{array}{l}\text { Gravel } \\
100\end{array}$} & \multirow{2}{*}{$\begin{array}{l}\text { C. soi } \\
100\end{array}$} \\
\hline & $40 \mathrm{~mm}$ & & \\
\hline Passing (\%) & $2 \mathrm{~mm}$ & 35 & 96 \\
\hline & $0.08 \mathrm{~mm}$ & 4 & 61 \\
\hline Sand equivalent (\%) & & 80 & - \\
\hline Los Angeles (\%) & & 23 & - \\
\hline Proctor optimum & MDD & - & 1.77 \\
\hline & Moisture & - & 19 \\
\hline CBR index (95\%) & & - & 7 \\
\hline Swelling (\%) & & - & 2 \\
\hline Plastic index (\%) & & - & 23 \\
\hline
\end{tabular}

the concrete. Besides, this value of the sand equivalent is higher than the minimum of $40 \%$ required for the base layer of T3 and T4 traffics (CEBTP 1980).

The plasticity index of this material is zero and its fines content is $4 \%$. These values are in accordance with the lack of coherence of this gravel. While, according to the CEBTP 1980, for soils with plasticity index of 0 , the fines content should be higher than $4 \%$ to be used in a base layer. Therefore, it is necessary to amend this gravel with a fine soil, a clayey soil for instance.

Geotechnical characteristics of the clayey soil: The plasticity index of this soil is $23 \%$ (Table 1 ), that is to say, in the range of the moderately clayey soils that can be used as a subbase layer, according to the CEBTP's classification (CEBTP, 1984). Its maximum swelling is $2 \%$, less than the maximum of $2.5 \%$ prescribed by the CEBTP 1980. However, at the optimum Proctor, the dry density is $1.77 \mathrm{t} / \mathrm{m}^{3}$, below the recommended minimum of $1.90 \mathrm{t} / \mathrm{m}^{3}$ and the optimum moisture content is $19 \%$, above the recommended maximum of $13 \%$ (CEBTP, 1980). Its CBR index after immersion is $7 \%$, far from the 30\% required by the CEBTP 1984 for subbase layer. Besides, it has a fines content of $61 \%$, which is twice the maximum of $30 \%$ recommended by the CEBTP 1980. Moreover, its particle size curve is above the grading envelope. According to the American Highway Research Board (HRB), this clayey soil belongs to the class A-6 which the general behavior as subbase layer varies from passable to bad.

Geotechnical characteristics of the mixtures: Figure 3 shows the grading grain size curves of the alluvial gravel mixed with the clayey soil at the contents varying from 5 to $30 \%$. As foreshadowed by the grading grains size curve of the washed alluvial gravel, only the $5 \%$ and the $10 \%$ curves remain in the CEBTP's grading envelope. The $15 \%$ curve is at the upper limit of this envelope, for the grains smaller than $2 \mathrm{~mm}$. But, considering the European grading envelope defined in the standard NF EN 13285, only the $25 \%$ and the $30 \%$ curves are above the allowed maximum limit for the grains smaller than $2 \mathrm{~mm}$.

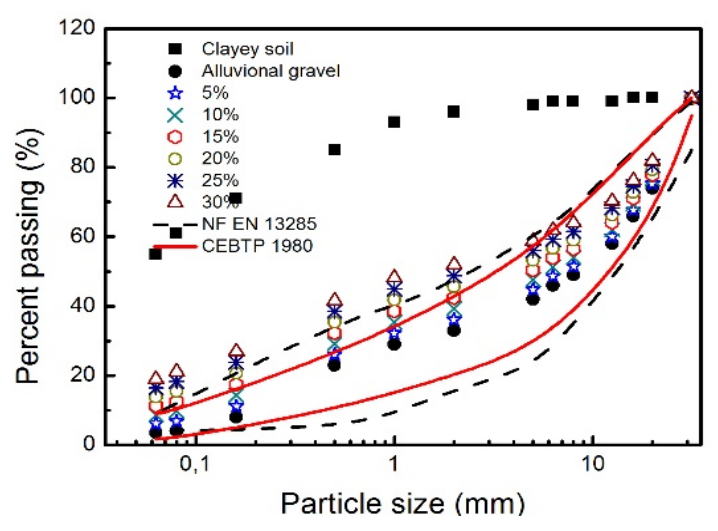

Fig. 3: Grading grain size curves of the mixtures of the alluvional gravel and the clayey soil at different content

Black dashed lines: The NF EN 13285 standard; Red solid lines: The CEBTP 1980 standard for the base layer in tropical countries

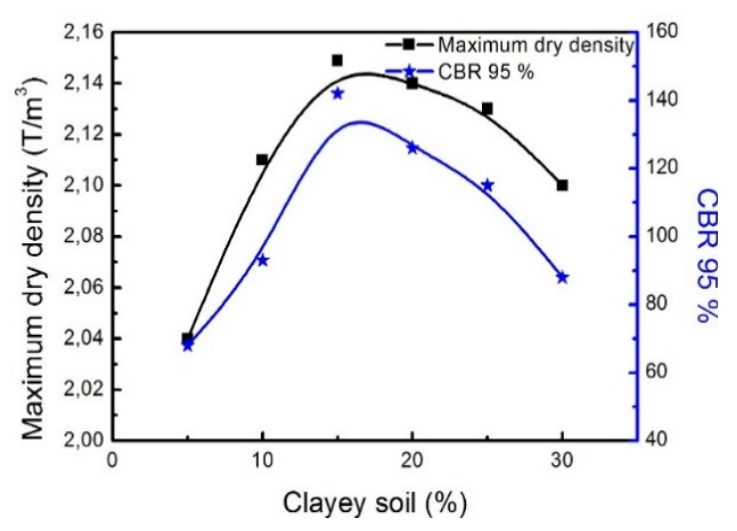

Fig. 4: The mixture maximum dry density and the CBR index versus the clayey soil content

Figure 4 shows the evolutions of the density (d) and the CBR index $\left(\mathrm{I}_{\mathrm{CBR}}\right)$ of the mixture according to the clayey soil content. It can be seen that these evolutions are very correlated and their maximum is reached with approximately $15 \%$ of the clayey soil. When the clayey soil content increases from 5 to $15 \%$, $\mathrm{I}_{\mathrm{CBR}}$ increases from 68 to $142 \%$. For the mixtures containing 7 to $30 \%$ of the clay soil, the CBR index is higher than the required $80 \%$ for the base layer use. It may also be noticed that the evolution of ICBR according to the density (d) is nearly parabolic, that indicates the great influence of the density and therefore the granularity of the mixture on its CBR index. Their relationship is the following one:

$I_{C B R}=31339-30510 d+7442 d^{2} ; R^{2}=0.995$

In order to simulate the crumbling of the material in use, the change of the percentage of fines during the modified Proctor test was determined. The observed increase in the percentage of fines is $<2 \%$. 


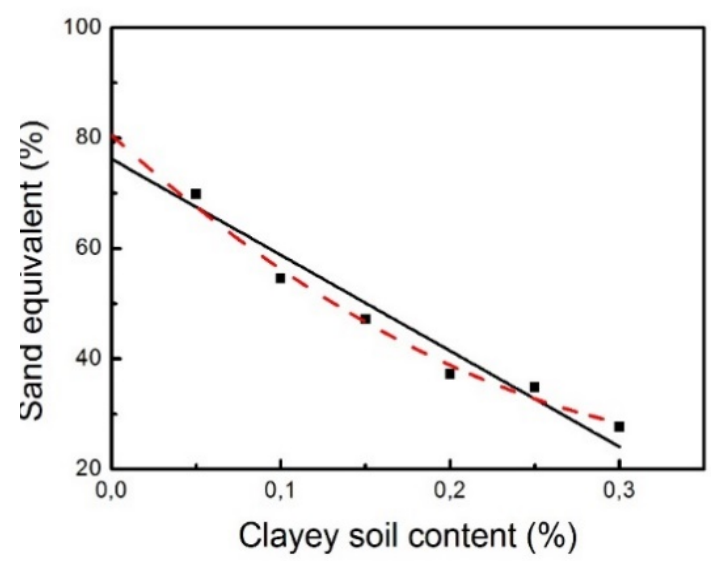

Fig. 5: Evolution of the sand equivalent of the mixture according to the clayey soil content in the mixture

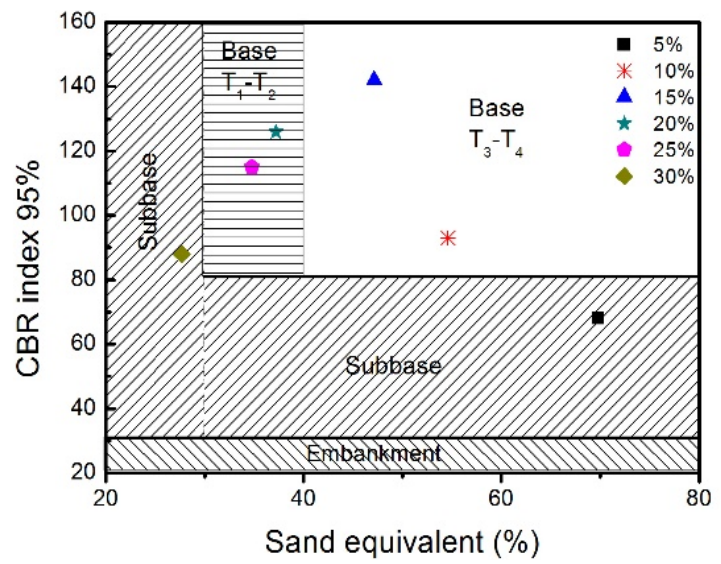

Fig. 6: Potential uses of the alluvional gravel-clayey soil mixtures according to the CEBTP 1980

Therefore, it is much lower than the maximum value of 8\% (CEBTP 1980). This result corroborates the low abrasion observed during the Los Angeles test.

The sand equivalent decreases from $80 \%$ for the raw alluvial gravel to $29 \%$ for the mixture with $30 \%$ of the clayey soil (Fig. 5). At the $\mathrm{I}_{\mathrm{CBR}}$ maximum, it is $46 \%$. All these values remain within the allowed limits.

As it can be seen on the curve, the Sand Equivalent (SE) of the mixture is not really proportional to the clay soil content $\left(\alpha_{\mathrm{cs}}\right)$. Indeed:

$$
\mathrm{SE}=76-174 \alpha_{\mathrm{cs}} ; \mathrm{R}^{2}=0.96
$$

Or:

$$
\mathrm{SE}=76-174 \alpha_{\mathrm{cs}}+346 \alpha_{\mathrm{cs}}^{2} ; \mathrm{R}^{2}=0.99
$$

Thus, the sand equivalent is not in accordance with the law of the mixtures, contrary to the sand content of the mixture. In other words, it is not proportional to the sand content of the mixture. Indeed, the sand content of the mixture $\mathrm{P}_{\mathrm{sm}}$ versus the clay soil content is given by the following equation:

$$
\mathrm{P}_{\mathrm{s}}^{\mathrm{m}}=\mathrm{P}_{\mathrm{s}}^{\mathrm{g}}+\left(\mathrm{P}_{\mathrm{s}}^{\mathrm{cs}}-\mathrm{P}_{\mathrm{s}}^{\mathrm{g}}\right) \alpha_{\mathrm{cs}}
$$

$\mathrm{Ps}_{\mathrm{s}}^{\mathrm{g}}$ and $\mathrm{Ps}^{\mathrm{cs}}$ are respectively the sand contents of the alluvial gravel and the clayey soil. If the sand equivalent of the mixture was proportional to the sand content of the mixture, it would also be the same with the clay soil content.

Figure 6 finds out the potential uses of the mixtures of the alluvial gravel and the clayey soil studied in the road construction, according to the CEBTP specifications of 1980 based on the CBR index and the sand equivalent. Depending on the clayey soil content, the mixture could be used as the subbase layer or the base layer for the $\mathrm{T} 1, \mathrm{~T} 2, \mathrm{~T} 3$ or $\mathrm{T} 4$ traffics. The compressive strength of the 10,15, 20 and the $25 \%$ mixtures is respectively $0.819,1.69,3.262$ and $3.257 \mathrm{MPa}$. Ageroute-Senegal (10) recommends a compressive strength of the lateritic base layer higher than $1.5 \mathrm{MPa}$. Thus, the $10 \%$ mixture could not be recommended as a base layer for T3 and T4 traffics.

\section{CONCLUSION}

The geotechnical characterization of the alluvial gravel of the Niari river has been conducted to assess its utilizations in the road construction. The results show that its grain size curve is in the base layer standard envelope, its Los Angeles coefficient and plasticity index are respectively 23 and $4 \%$. To enhance its plasticity and CBR index, it has been stabilized with a clayey soil. The CBR index increases from 0 for raw gravel to the maximum of $146 \%$ when mixed with $15 \%$ of the clayey soil, while the sand equivalent decreases from 80 to $46 \%$. According to the CEBTP standards, the blends with 5, 10 and 30 , respectively of the clayey soil could be used as the subbase layer in the road construction; that with $15 \%$ as the base layer for T3 and T4 traffics and those with 20 and $25 \%$ as the base layer for T1 and T2 traffics. Besides, it is found that the CBR index of the mixture is strongly correlated to its density and the relationship between them is parabolic.

\section{ACKNOWLEDGMENT}

The authors thank le Bureau de Contrôle du Bâtiment et Travaux Publics (BCBTP) of Congo for its assistance.

\section{REFERENCES}

Bohi, Z.P.B., 2008. Caractérisation des sols latéritiques utilisés en construction routière: cas de la région de l'Agneby (Côte d'Ivoire). Ph.D. Thesis, Ecole Nationale des Ponts et Chaussées, Paris.

Camapum de Carvalho, J., L.R. de Rezende, F.B.F. Cardoso, L.C.F.L. Lucena, R.C. Guimarães and Y.G. Valencia, 2015. Tropical soils for highway construction: Peculiarities and considerations. Transportation Geotechnics, 5: 3-19. 
CEBTP (Centre Expérimental du Bâtiment et Travaux Publics), 1984. Guide pratique de dimensionnement des chaussées pour les pays tropicaux. Minestère de la coopération, France.

Centre Expérimental de recherches et d'études du Bâtiment et Travaux Publics (CEBTP), 1980. Guide pratique de dimensionnement des chaussées pour les pays tropicaux. Minestère de la coopération, France.

Cocks, G., R. Keeley, C. Leek, P. Foley, T. Bond, A. Crey, P. Paige-Green, S. Emery, R. Clayton, D. McIness and L. Marchant, 2015. The use of naturally occuring materials for pavements in Western Australia. Austalian Geomechanics, 50: 43-106.

Correia, A.G., M.G. Winter, A.J. Puppala, 2016. A review of sustainable approaches in transport infrastructure geotechnics. Transportation Geotechnics, 7: 21-28. Economic Commission for Africa, 2007. Transport situation in Africa. United Nations, Cinquième session du Comité de Commerce et Coopération et de l'intégration régionale, Addis Abeba. E/ECA/CTRCI/5/3.

Issiakou, M.S., 2016. Caractéisation et valorization des matériaux latéritiques utilisés en construction au Niger. Ph.D. Thesis, Université de Bordeaux, Bordeaux.

Kana, E.M., 2016. Geotechnical engineering practice for road works in tropical regions of Africa. Lettre Afrigeo, 2: 3-11.

Molenaar, A.A.A., 2013. Durable and sustainable road constructions for developing countries. Procedia Engineer., 54: 69-81.

Ndiaye, M., 2013. Contribution à l'étude des sols latéritiques du Sénégal et du Brésil. Ph.D. Thesis, Université de Paris-Est, Paris. Sangaré, M. and S. Atiase, 1991. Synthèse de données sur l'entretien et la réhabilitation des routes rurales en Afrique de l'ouest et du centre. Projet d'appui au développement africain $\mathrm{n}^{\circ}$ 698-0464. 28. 19.

NF EN 13285, 2006. Grave non traité - Spécifications. Comité français pour les techniques routières. Association Française de Normalisation (AFNOR). www.afnor.fr.

NF EN 13286-41, 2007. Essai résistance compression des sols traité. Association Française de Normalisation (AFNOR). www.afnor.fr.

NF P18-573, 1990. Aggregates Los Angeles Test. Association Française de Normalisation (AFNOR). www.afnor.fr.
NF P18-597, 1990. Aggregates. Détermination of clean liness for fines aggregates: Sand equivalent with $10 \%$ fines. Association Française de Normalisation (AFNOR). www.afnor.fr.

NF P94-051, 1993. Soils: Investigation and testing Determination of Atterberg limits - liquid limit test using casagrande apparatus - plastic limit test on rolled thread. Association Française de Normalisation (AFNOR). www.afnor.fr.

NF P94-056, 1996. Soil: Investigation and testing Granulometric analysis - Dry sieving method washing. Association Française de Normalisation (AFNOR). www.afnor.fr.

NF P94-057, 1992. Analyse granulométrique des sols. Méthode par sédimentation. Association Française de Normalisation (AFNOR). www.afnor.fr.

NF P94-078, 1997. Soils: Investigations and tests CBR after immersion-Immediate bearing ratio. Measurement on sample compacted in CBR mould. Association Française de Normalisation (AFNOR). www.afnor.fr.

NF P94-093, 1999. Soils: Investigations and testing Determination of compaction characteristics of soil - Standard Proctor test - Modified Proctor test. Association Française de Normalisation (AFNOR). www.afnor.fr.

Onana, V.L., A. Ngo'o Ze, R. Medjo Eko, R.F.D. Ntouala, M.T. Nanga Bineli, B. Ngono Owoudou and G.E. Ekodeck, 2017. Geological identification, geotechnical and mechanical characterization of charnockite-derived lateritic gravels from Southern Cameroon for road construction purposes. Transportation Geotechnics, $10: 35-46$.

Paige-Green, P., M. Pinard and F. Netterberg, 2015. A review of specifications for lateritic materials for low volume. Transportation Geotechnics, 5 : 86-98.

Quadri, H.A., O.A. Adeyemi and O.S. Olafusi, 2012. Investigation of the geotechnical engineering properties of laterite as a subgrade and base material for road constructions in Nigeria. Civil Environ. Res., 2: 23-31.

Sinha, K., A Varma, M.P. Walsh and A. Faiz, 1990. Environmental and Ecological Considerations in Land Transport: A Resource Guide. Banque mondiale, Washington.

Toll, D.G., 1991. Towards understanding the behaviour of naturally-occurring road construction materials. Geotechnical and Geological Engineering, 9: 197-217.

Weinert, H.H., 1980. The Natural Road Construction Materials of Southern Africa. Academica, Pretoria, Cape Town. 